\title{
PERANCANGAN E-REPORT FINANCIAL SYSTEM BERBASIS WEB (STUDI KASUS : TOKO KRIPIK BALADO MAHKOTA)
}

\author{
Fanny Oktavia ${ }^{1 *}$, Yeka Hendriyani ${ }^{2}$ \\ ${ }^{1}$ Program Studi Pendidikan Teknik Informatika, Universitas Negeri Padang, Indonesia \\ ${ }^{2}$ Program Studi Pendidikan Teknik Informatika, Universitas Negeri Padang, Indonesia \\ Jl. Prof. Hamka Kampus UNP Air Tawar Padang \\ *Corresponding Author: fannyoktavia95@gmail.com
}

\begin{abstract}
ABSTRAK
Tujuan dari penelitian ini adalah untuk merancang e-report financial system berbasis web yang akan diterapkan pada toko Kripik Balado Mahkota baik itu laporan penjualan, pembelian serta laba rugi, maupun transaksi jual beli antar supplier dan antar pembeli toko. Dimana dalam sistem yang diterapkan di toko Kripik Balado Mahkota masih memiliki permasalahan dalam pelaporan seperti perbedaan antara laporan dan hasil dari jual beli, faktur pembelian ganda dari supplier, dan pelaporan barang ataupun transaksi masih bersifat manual. Metode perancangan yang digunakan dalam sistem e-report financial yaitu pemakaian teknik arsitektur MVC (Model, View and Controller), dipadukan dengan menggunakan Framework Yii2 dan PHP, dengan media penyimpanan dengan database tools MySQL, dan model perancangan UML use case, activity diagram serta class diagram. Hasil dari perancangan e-report financial ini adalah tersedianya laporan yang bersifat elektronik, mudah diakses dimanapun dan kapanpun, dan juga meminimalisir data yang rancu dan tumpang tindih. Maka perancangan e-report financial ini mempermudah dalam pembuatan laporan dengan model perancangan, metode perancangan dan media yang mendukung dan di terapkan dalam sistem e-report financial.
\end{abstract}

Kata kunci: E-report financial, Framework yii2, Toko Kripik Balado Mahkota, arsitektur MVC

\begin{abstract}
The purpose of this observation is to contrive the e-report financial system that will be use on kripik balado mahkota store like the sales reporting, purchase reporting, profit and loss, and transaction of sales and purchases from suppliers or buyers. The old system in Kripik Balado Mahkota store still have problems like the report and the outcome of selling and buying are mismatched, had the multiple purchase invoice from supplier, and reports of goods or transaction are still manual report. The method of design that will be used in the e-report financial system is using architectural MVC (model, view, and controller)techniques, combined with framework yiiz and PHP, storage media with database tool MySQL, and UML's model design use case diagram, activity diagram, and class diagram. The results of e-report financial's design are the electronic report will be available, easily accessible everywhere and every time, also minimize the redundant data and overlap data. So the design of the e-report financial system making the report so easily with the model, method, and supporting media that be used in the system.
\end{abstract}

Keywords: E-report financial, Framework Yii2, Kripik Balado Mahkota store, $M V C^{\prime}$ s architecture 


\section{PENDAHULUAN}

Dalam meningkatkan dan mengembangkan sistem pelaporan, maka toko Kripik Balado Mahkota membutuhkan pelaporan berbasis teknologi web agar bisa di akses dengan mudah. Pelaporan yang masih bersifat manual, kemudian data transaksi atau laporan jual beli pada toko tersebut mengalami redudansi data dan banyak data yang tumpang tindih. Banyaknya kekeliruan dalam penghitungan data barang masuk, terjual ataupun keluar, dan proses data yang masih manual. Sehingga dengan adanya sistem yang baru akan secara jelas hasil yang di tampilkan dalam laporan penjualan, pembelian, laba rugi, data supplier, dan stok barang yang ada di toko.

Pengaplikasian e-report ini bertujuan untuk menghasilkan pelaporan harian, bulanan serta tahunan secara realtime dan tanpa adanya tumpang tindih antara laporan yang satu dengan yang lainnya. Serta meminimalisir kesalahan dalam pembuatan laporan atau kehilangan data yang cukup besar tanpa mengurangi fungsi laporan sebagai manajemen dalam perkembangan atau pelaporan segala hal kegiatan yang terkait dengan fungsi dan tugas suatu perusahaan[1].

Disamping itu laporan keuangan sangat penting dalam menginformasikan atau mengkomunikasikan keuangan di luar pihakpihak suatu instansi atau perusahaan agar tidak terjadi suatu kesalahan yang mengakibatkan missed komunikasi atau keterlambatan pelaporan tersebut ke pihak pimpinan perusahaan atau instansi [2].

Maka dalam perancangan sistem menggunakan metode UML seperti use case diagram sebagai gambaran antara interaksi dua komponen seperti actor dan sistem. Actor merupakan komponen yang mempunyai hubungan langsung dengan sistem yang memiliki banyak use case yang dimana use case bisa berinteraksi dan di proses dengan beberapa actor[3].

Kemudian dalam pengaplikasiannya ini, MySQL sebagai manajemen data didalam sistem yang tentunya sangat mudah digunakan, lalu memiliki kinerja yang cepat dalam penyimpanan data[4]. Dengan menggunakan arsitektur dari Yii seperti MVC akan memudahkan dalam hal pemisahan logic business dengan interface user , supaya memudahkan developer untuk mengganti setiap bagian tanpa mempengaruhi bagian lainnya[5].

Tanpa mengurangi fungsi dari laporan keuangan sebagai tindakan dalam mengambil suatu keputusan dan menganalisis keuangan suatu perusahaan untuk mengetahui bagaimana hasil keuangan yang sudah didata secara berjangka agar dapat menentukan analisis keuangan berdasarkan keuntungan atau kerugian yang didapatkan dari perusahaan tersebut[6].

Dengan menggunakan metode dari context diagram, dapat digambarkan lingkup dari sistem yang telah di rancang, sehingga dapat dianalisis input-an data ke sistem dan output yang diberikan sistem ke user baik berupa laporan atau informasi lainnya[7].

Maka dari itu dibutuhkan teknologi berbasis web dimana mengkombinasikan antara PHP dan framework Yii2 yang memiliki komponen berkinerja besar dan dapat digunakan dalam merancang atau membangun aplikasi yang tentunya modern dengan cepat[8].

\section{METODE}

Suatu pengiriman data yang bersifat atau berbasis media teknologi informasi disebut sebagai layanan elektronik. Layanan ini memberikan fasilitas bagi lembaga yang bersangkutan untuk mengumpulkan data-data penting tertentu yang diperlukan. Fleksibilitas diberikan dalam layanan eletronik agar memudahkan pengumpulan data. Tingkat kesalahan dalam menginput data seperti yang terjadi pada input ulang manual pun dikurangi yang mungkin akan lebih memakan waktu yang lebih lama dalam proses penyajian datanya[9].

Pelaporan sebagai sarana yang penting dalam menyampaikan informasi keuangan suatu perusahaan untuk mengetahui penentuan posisi dari suatu perusahaan atau hubungan kerjasama antar perusahaan lainnya[10]. Kemudian laporan ini akan dirancang se-modern mungkin. Dengan mengkombinasikan antara PHP dan framework yii2 yang memiliki komponen berkinerja besar untuk digunakan dalam merancang atau membangun aplikasi[11] dan memakai konsep dari framework yii2 seperti model, controller dan view yang bisa memisahkan antara logika bisnis dari pertimbangan interface user, agar developer mampu mengubah beberapa bagian tanpa mempengaruhi yang lainnya[12].

Analisis ini tercakup dalam analisis yang terjadi saat ini, kemudian analisis aturan bisnis, analisis pelaku, analisis masalah dan solusi, analisis yang telah diusulkan dan analisis dalam kebutuhan sistem[13]. Dalam sistem yang berjalan saat ini, user masih melakukan pelaporan baik itu penjualan, pembelian, retur barang, barang, maupun laba rugi yang bersifat manual. Maka tidak jarang jika ada laporan bersifat tumpang tindih dan rancu. Sesuai dengan fungsinya, laporan keuangan 
digunakan dalam menampilkan atau menunjukkan kondisi keuangan yang terjadi setiap waktu pada suatu perusahaan[14].

Dalam analisis input dan output pada sistem e-report ini, meliputi halaman penginputan dan menampilkan hasil yang dibutuhkan oleh user berupa pelaporan. Sesuai dengan level dari masingmasing admin, maka output dari setiap user pun juga akan berbeda dan tentunya sesuai dengan kebutuhan sistem[15].

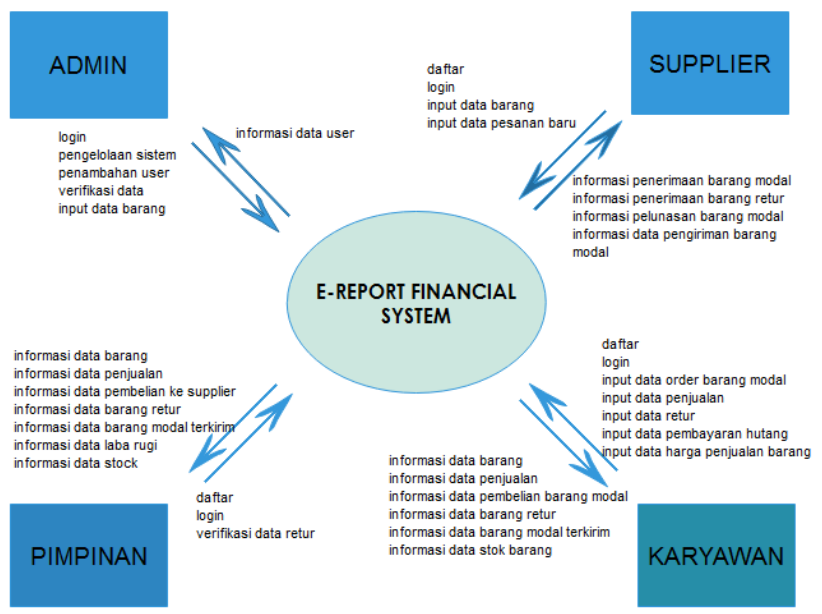

Gambar 1. Context Diagram E-report Financial System Berbasis Web

Context diagram berfungsi sebagai pendefinisian dalam sistem dan mengevaluasi setiap permasalahan agar dapat dianalisis dan diusulkan suatu perbaikan sesuai dengan kebutuhan yang diinginkan[16]. Pada context diagram dijelaskan bahwa e-report financial system ini mempunyai beberapa user yang memiliki input dan outputannya masing-masing. Dimana admin bertugas dalam mengelola sistem dan memverifikasi data setiap user atau menambahkan data user. Namun output pada admin hanya akan memiliki data laporan informasi data user. Kemudian pada user supplier hanya dapat menginput data barang yang akan dimasukkan ke dalam toko, dan penginputan verifikasi barang pesanan baru dari toko. informasi yang didapatkan oleh supplier , berupa laporan retur barang, pemesanan barang, penerimaan barang yang akan disupply oleh supplier.

User karyawan bertugas dalam penginputan data order barang, data penjualan, data retur, data pembayaran hutang dan data harga penjualan barang. Dan hanya menerima output seperti informasi data barang, data penjualan, data pembelian barang modal, data barang yang suda diretur, data barang modal yang terkirim, dan data stok barang yang ada. Kemudian ada pimpinan memiliki akses memverifikasi data seperti data retur dan data penyetujuan barang modal untuk dimasukkan ke dalam toko. Dalam outputannya, pimpinan menerima lebih banyak informasi seperti informasi data barang, data penjualan, data pembelian, data supplier, data retur barang, data laba rugi , data stok barang, data hutang baik itu harian, bulanan, maupun tahunan.

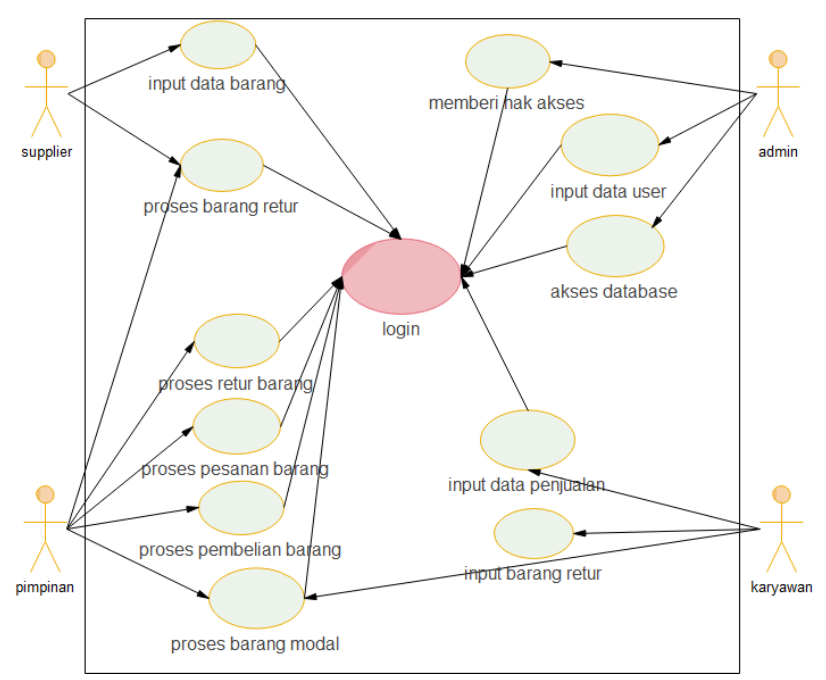

Gambar 2. Use case Diagram E-report Financial System Berbasis Web

Use case diagram menunjukkan proses yang terjadi dalam sistem. Dimana ketika saat login, masing-masing user memiliki peran. Admin memberi hak akses, kemudian menginput data user dan mengakses database pada sistem[17]. Pimpinan memproses segala hal yang berkaitan dengan retur barang, pemesanan barang, pembelian barang, dan memproses barang yang baru masuk dari supplier dengan user karyawan. User karyawan mempunyai akses dalam penginputan barang penjualan, modal dan retur barang. Kemudian supplier hanya menginput data barang dan memproses data barang yang akan diretur nantinya.

Analisis kebutuhan fungsional digunakan untuk memaparkan fitur-fitur yang akan dimasukkan ke dalam aplikasi yang dibuat[18]. Selain itu yang dimaksud dengan kebutuhan fungsional yaitu aktivitas dan layanan yang harus disediakan oleh sistem. Fitur-fitur yang ada pada $E$ report financial system Kripik Balado Mahkota berbasis web ini adalah sebagai berikut: 
Tabel 1. Persyaratan Fungsional E-report Financial System Berbasis Web

\begin{tabular}{|c|c|c|}
\hline No & Fungsional & Keterangan \\
\hline 1 & $\begin{array}{l}\text { Login untuk user yang } \\
\text { memiliki usemame dan } \\
\text { password }\end{array}$ & $\begin{array}{l}\text { Sistem hanya akan } \\
\text { memberikan fasilitas } \\
\text { login untuk user yang } \\
\text { meiliki usemame dan } \\
\text { password contoh } \\
\text { pimpinan }\end{array}$ \\
\hline 2 & Hak Akses & $\begin{array}{l}\text { Sistem ini mendukung } \\
\text { sistem hak akses } \\
\text { unutk memudahkan } \\
\text { dalam hal } \\
\text { menginputkan data, } \\
\text { jadi dengan adanya } \\
\text { hak akses user hanya } \\
\text { biasa menginputkan } \\
\text { data sesuai haknya } \\
\text { dalam sistem. }\end{array}$ \\
\hline 3 & $\begin{array}{l}\text { Memberikan Fasilitas } \\
\text { CRUD }\end{array}$ & $\begin{array}{l}\text { Unutk melakukan } \\
\text { CRUD user harus } \\
\text { memiliki username } \\
\text { dan password yang } \\
\text { akan melakukan } \\
\text { CRUD sesuai dengan } \\
\text { haknya }\end{array}$ \\
\hline 4 & Fitur Pencarian Data & $\begin{array}{l}\text { Sistem akan } \\
\text { memberikan fasilitas } \\
\text { pencarian data agar } \\
\text { mempermudah dalam } \\
\text { merubah atau melihat } \\
\text { satu data saja }\end{array}$ \\
\hline
\end{tabular}

Kemudian model perancangan dalam sistem e-report financial ini menggunakan UML berupa activity diagram dan class diagram. Activity diagram mendesain segala bentuk proses yang terjadi pada sistem dengan dipresentasikan dalam bentuk diagram dan menjelaskan aktivitas antar user dan sistem[19]. Namun masing-masing user memiliki level akses yang berbeda untuk mengakses data yang ada pada sistem e-report financial ini[20].

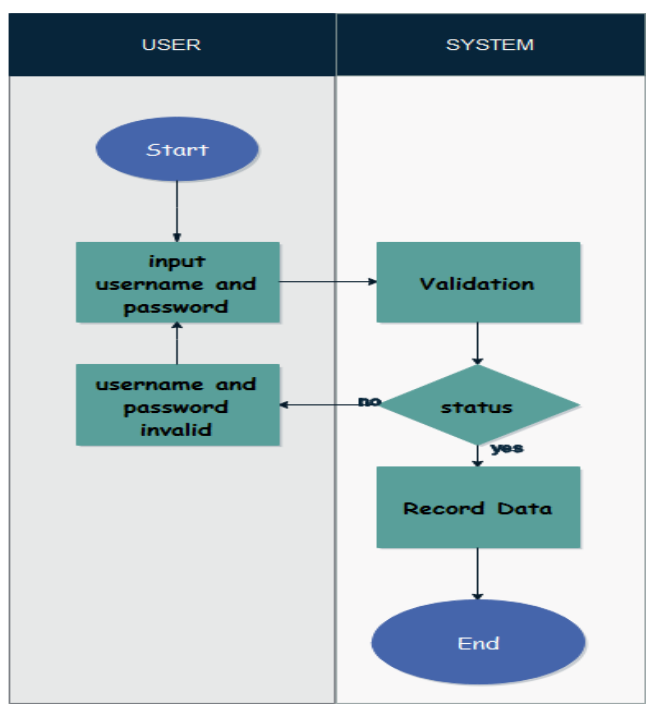

Gambar 3. Activity diagram Login sistem E-report Financial System Berbasis Web
Pada gambar 3 dijelaskan activity diagram dalam melakukan aktivitas login user ke sistem. Jika user melakukan kesalahan dalam peinputan data seperti kesalahan dalam memasukkan username atau password, maka proses akan dikembalikan ke form login. Jika data yang dimasukkan benar, sistem akan merecord data dan user akan masuk ke sistem e-report.

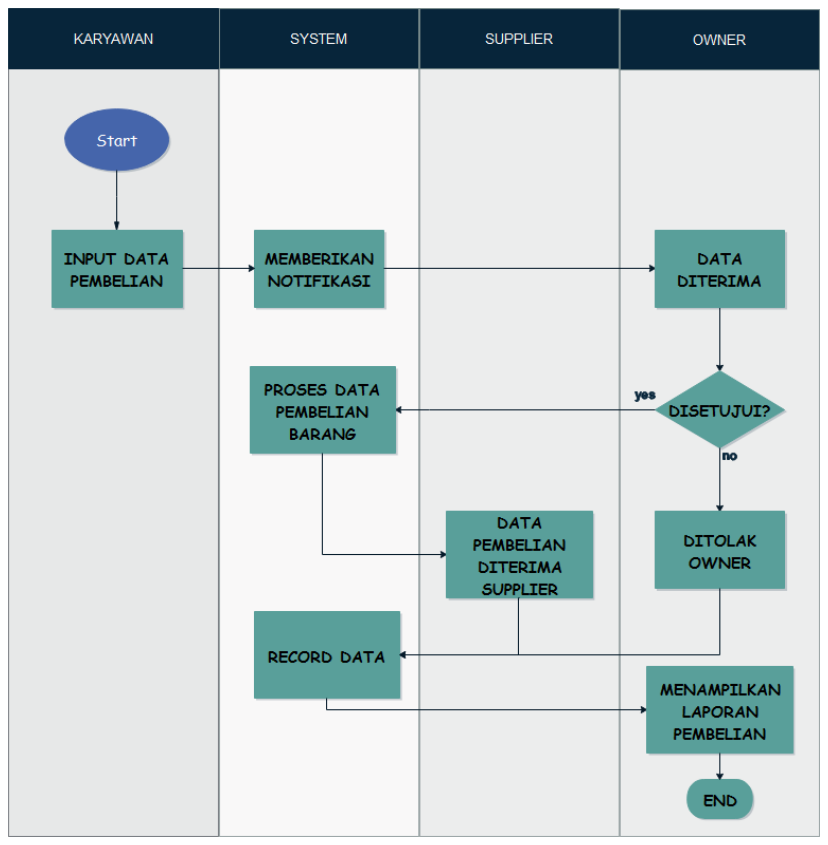

Gambar 4. Activity diagram Pemesanan Barang Modal pada Ereport Financial System Berbasis Web

Pada gambar 4 dijelaskan pada activity diagram mengenai aktivitas dalam pemesanan barang. Dimana karyawan terlebih dahulu menginput data barang yang akan dipesan, kemudian data tersebut akan diteruskan ke owner untuk disetujui. Jika disetujui maka data akan diteruskan dengan diproses oleh sistem terlebih dahulu, kemudian data akan diterima oleh supplier dan dilakukan proses selanjutnya. 
Volume 13, No. 1, Edisi Maret 2020

http://tip.ppj.unp.ac.id

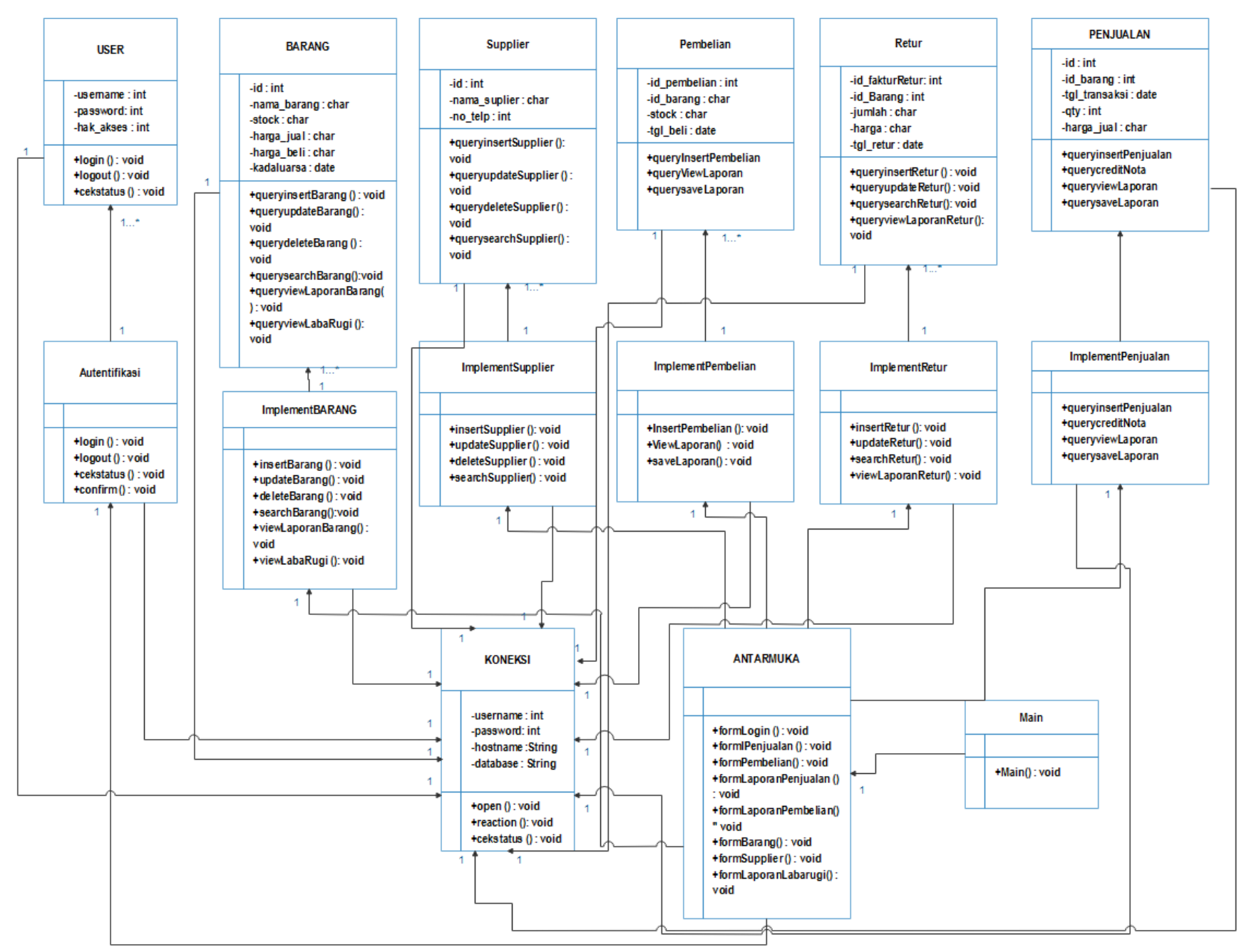

Gambar 5. Class Diagram E-report Financial System Berbasis Web

Class diagram e-report financial systemini dijelaskan semua entitas memiliki koneksi satu sama lain. Seperti pada autentifikasi memiliki hubungan kebanyak user namun satu user hanya bisa melewati satu kali autentifikasi. ImplementBarang memiliki akses kebeberapa barang namun hanya bisa sekali penginputan untuk barang dengan kategori tertentu. Masingmasing user pun juga memiliki satu kali akses setiap kali login kesemua data yang ada pada sistem e-report financial system ini terlihat pada gambar 5.

\section{HASIL DAN PEMBAHASAN}

Berdasarkan dari perancangan yang telah diuraikan, maka didapatkan hasil perancangan tampilan dari e-report financial system ini. Pertama dilakukan login terlebih dahulu dalam mengakses sistem e-report ini.

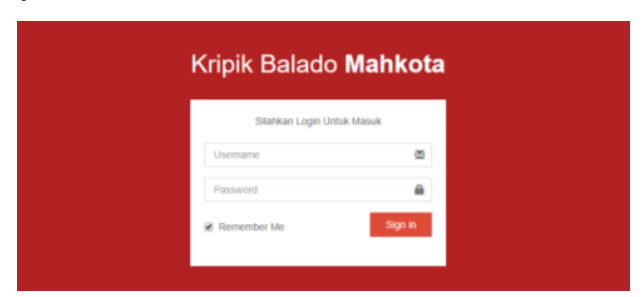

Gambar 6. Tampilan Login Page E-report Financial System Berbasis Web

Sebelumnya admin terlebih dahulu memberikan hak akses sesuai dengan kebutuhan masing-masing user. Terlihat pada gambar 6 , tampilan pada halaman Login terdapat nama dari form loginnya, kemudian kolom penginputan nama user dan password yang harus diisi ketika ingin masuk kedalam sistem.

Kemudian masuk ke Home Page, dalam Home Page akan tampil suatu grafik yang berisi hasil dari penjualan barang yang paling banyak terjual. Dalam grafik ini ditampilkan beberapa barang yang terjual yang diinputkan sebelumnya dalam form penjualan barang. 


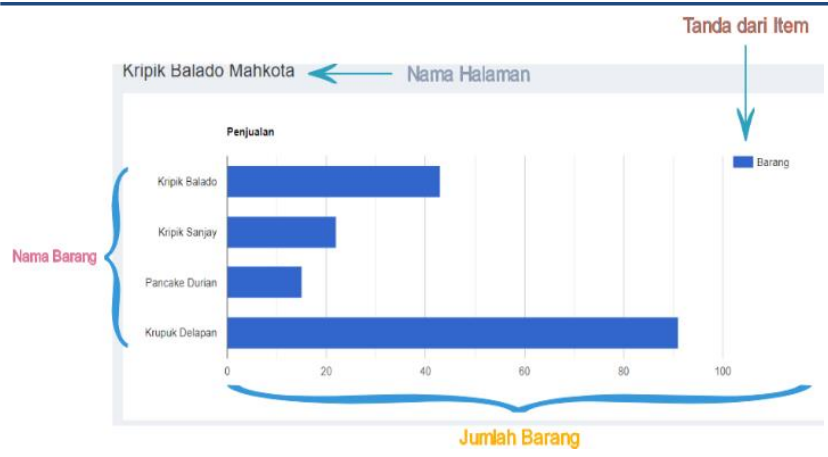

Gambar 7. Home Page Hasil Penjualan Pada Pimpinan dan Karyawan pada E-report Financial System Berbasis Web

Grafik penjualan hanya ditampilkan pada user tertentu saja seperti user untuk pimpinan dan karyawan . Dijelaskan bahwa terdapat nama barang yang terjual, kemudian jumlah barang yang terjual dan tanda dari item seperti yang dilihat pada gambar 7.

Kemudian berikut adalah tampilan dari Home Page untuk user Supplier. Dimana akan ditampilkan berupa berapa banyak barang yang sudah diterima atau terkirim, kemudian informasi retur barang yang diinputkan oleh karyawan dan disetujui oleh owner toko sebelumnya.

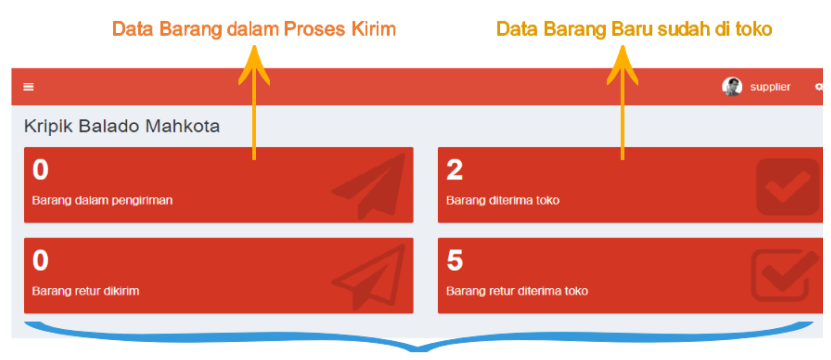

Data Barang Retur

Gambar 8. Tampilan pada Homepage User Supplier di E-report Financial System Berbasis Web

Data dari halaman supplier dimana dijelaskan barang yang sedang dalam proses kirim, lalu data barang yang dikirim oleh supplier sudah diterima oleh pihak toko, lalu data barang rusak yang dikirimkan oleh pihak toko ke supplier, di jelaskan dalam gambar 8.

Berikut ini merupakan tampilan dari laporan list barang yang telah dimasukkan oleh admin. Pada list laporan barang ini terlihat berapa jumlah stok yang tercantum, lalu harga dari setiap barang yang terdata.

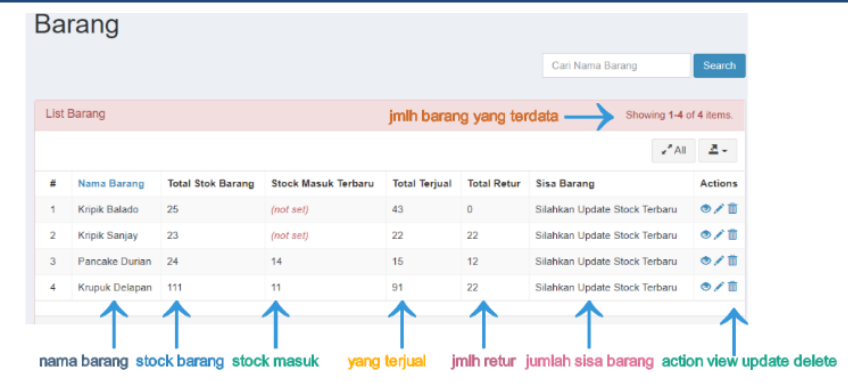

Gambar 9. Tampilan Laporan List Barang pada E-report Financial System Berbasis Web

Selanjutnya web page dari list barang, dengan rincian berupa nama barang yang terdata, kemudian total stock barang yang ada, kemudian stock masuk dari supplier, data yang terjual dari sistem penjualan, sisa barang yang ada pada toko, dan beberapa tombol aksi untuk melihat detail perbarang, menghapus atau mengupdate barang tersebut yang dijelaskan pada gambar 9.

Pada halaman order barang, karyawan akan memesan terlebih dahulu dan tentunya nomor faktur akan keluar secara otomatis, kemudian karyawan diminta untuk menginputkan barang mana yang akan di pesan ke supplier, yang nantinya akan disetujui oleh owner.

ketika penginputan selesai, akan muncul halaman, dimana transaksi pemesanan barang telah sukses dan akan di teruskan laporannya kepada owner untuk di tindaklanjuti, apakah pemesanan barang disetujui owner atau tidak. Maka akan ditampilkan transaksi dari pembelian barang tersebut.

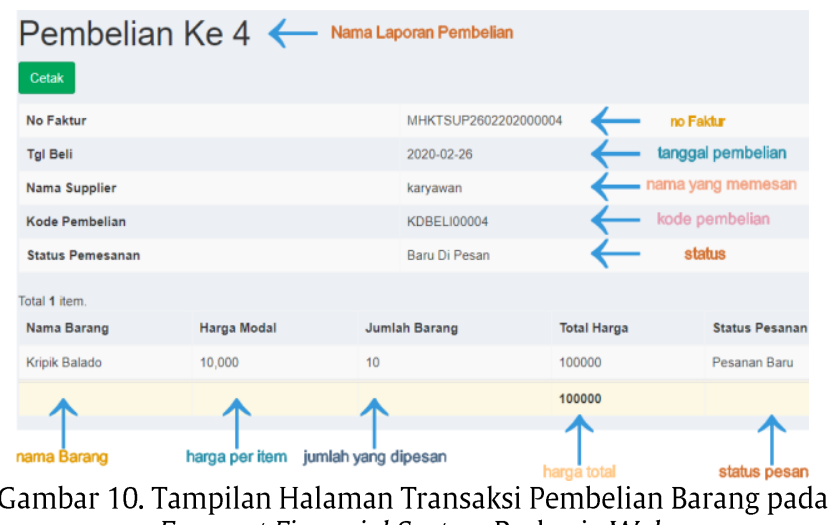

E-report Financial System Berbasis Web

Berikut ini merupakan tampilan halaman pembelian barang, dengan data pembelian atau pemesanan yang keempat. Dirincikan dari nomor faktur pemesanan, kode pembelian, tanggal pembelian barang, nama supplier yang memesan, status pemesanan barang. Dan didata nama barang dan jumlah barang yang dipesan beserta harga dari masing-masing item dilihat pada gambar 10. 
Pada halaman ini merupakan list pesanan yang sukses dan sudah diterima laporannya oleh owner, yang kemudian akan diteruskan ke supplier, dimana barang tersebut akan disiapkan oleh supplier dan dikirimkan ke toko.

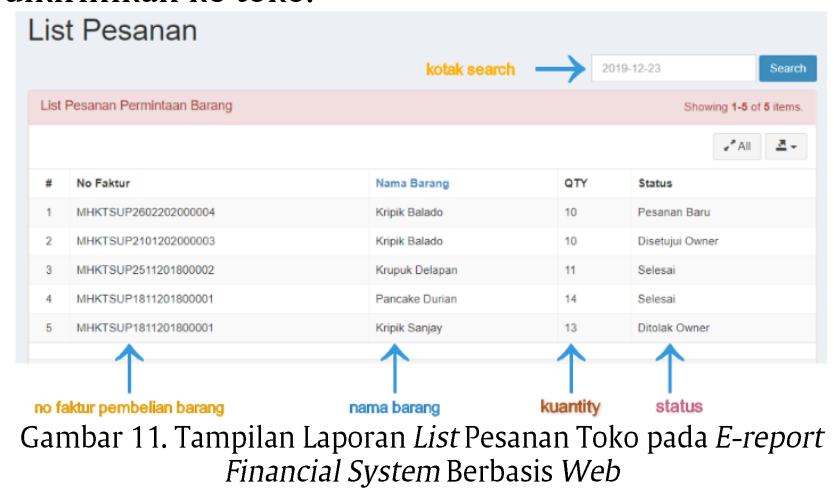

Selanjutnya tampilan dari laporan list barang, dengan rincian berupa nomor dari faktur pembelian barang, lalu nama barang yang dipesan dan jumlah yang akan dipesan beserta status dari barang tersebut apakah ditolak oleh owner, baru memesan atau sudah selesai pada gambar 11.

Lalu tampilan untuk halaman retur barang yang merupakan list laporan dari barang retur atau barang yang sudah tidak layak konsumsi yang akan dikembalikan ke supplier. Barang retur akan muncul ketika user karyawan melakukan penginputan sebelumnya berapa banyak barang yang rusak atau tidak layak dikonsumsi.

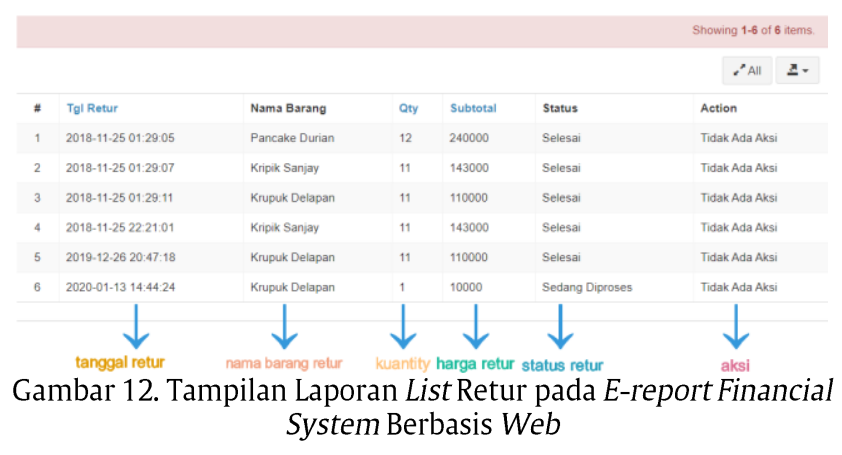

Tampilan berikutnya merupakan rincian dari list dari retur barang dimana nama barang , tanggal retur barang, jumlah barang yang di retur, harga total barang yang diretur dan aksi yang akan di gunakan dalam proses retur barang supplier. Jika pengembalian barang sudah selesai maka akan keluar status selesai jika masih diproses oleh supplier maka akan dirincikan status sedang dalam proses seperti pada gambar 12 .

Print out laporan penjualan menunjukkan barang yang telah terjual di toko. Dari laporan penjualan ini akan terlihat berapa besar laba dan rugi yang telah didapat dari penjualan di toko kripik balado mahkota.

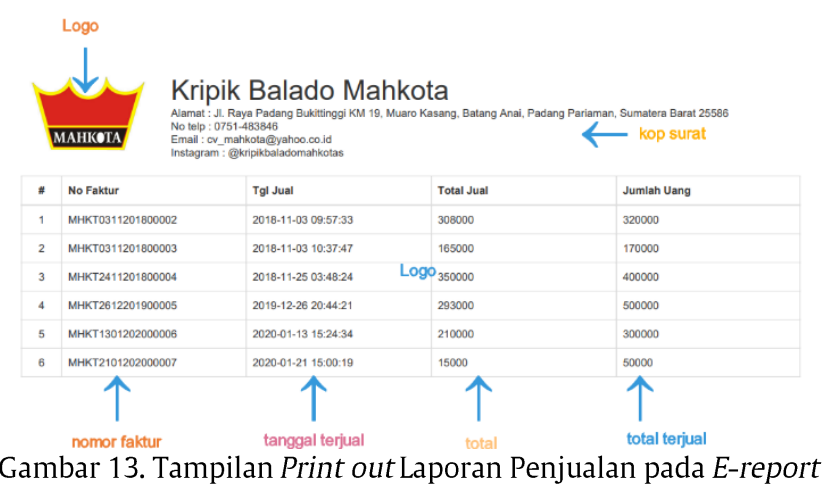
Financial System Berbasis Web

Pada tampilan web berikutnya, menunjukkan rincian dari laporan penjualan dengan nomor faktur , tanggal terjual , lalu harga dari barang yang terjual, dan total harga dari barang yang terjual seperti pada gambar 13.

Print out laporan pembelian menunjukkan barang modal yang telah disetujui atau ditolak oleh owner. Barang pemesanan ke supplier akan berstatus selesai ketika supplier juga menyetujui pembelian barang.

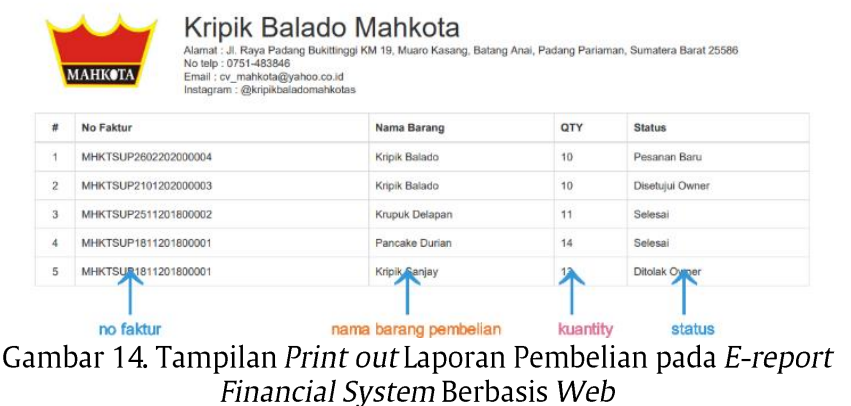

Laporan pembelian barang dengan nomor faktur yang tercantum, nama barang yang akan dibeli dan jumlah dari pembelian barang, dan status dari pembelian barang tersebut, pada gambar 14 .

\section{KESIMPULAN}

Dengan adanya website e-report financial system dapat menghasilkan pelaporan harian, bulanan serta tahunan yang dibuat secara manual ke dalam versi website, dapat mampu membuat website responsive, menampilkan kelebihan maupun keunikan website yang digunakan library Yii 2 Framework. Dan akan mempermudah dalam proses pelaporan baik itu laporan penjualan, laporan pembelian dan laba rugi, serta mengurangi sistem lama yang masih bersifat manual. 


\section{SARAN}

Adapun saran yang diberikan setelah merancang dan membangun sistem e-report ini, antara lain :

1. Dengan adanya Website ini dapat membantu dalam menyimpan data yang nantinya bisa di akses kapan saja dan dimana saja oleh pihak Toko Kripik Balado Mahkota.

2. Dapat mempermudah dalam hal pelaporan dan memberikan informasi yang akurat tentang laba rugi dan peningkatan jumlah penjualan oleholeh khas minang baik itu perbulan atau pertahun.

3. Dapat menambah wawasan dan pengembangan potensi di bidang teknologi informasi serta memperluas wawasan tentang pengelolaan hasil penjualan dan pembelian menggunakan $E$ report khususnya di Toko Kripik Balado Mahkota.

4. Dapat mempermudah dalam hal penyuplaian barang modal, baik itu barang yang akan dipesan atau barang yang akan dikembalikan karena kondisi barang yang tidak baik lagi. Dan juga mempercepat proses pengiriman barang modal yang di pesan oleh pihak Toko Kripik Balado Mahkota.

\section{DAFTAR PUSTAKA}

[1] R. Y. Endra and D. S. Aprilita, " E-report Berbasis Web Menggunakan Metode Model View Controller Untuk Mengetahui Peningkatan Perkembangan Prestasi Anak Didik," Explor. - J. Sist. Inf. dan Telemat., vol. 9, no. 3, pp. 15- 22, 2018.

[2] A. H. Umy Mukhofifah, Migunani, "Perancangan Sistem Pelaporan Keuangan Berbasis Web," IJSE-Indonesian J. Softw. Eng., vol. 2, no. 1, pp. 15- 24, 2016.

[3] T. A. Kurniawan, "Pemodelan Use Case (UML): Evaluasi Terhadap beberapa Kesalahan dalam Praktik," J. Teknol. Inf. dan Ilmu Komput., vol. 5, no. 1, p. 77, 2018, doi: 10.25126/jtiik.201851610.

[4] H. Yuliansyah, P. Studi, T. Informatika, and U. Ahmad, "Perancangan Replikasi Basis Data Mysql Dengan Mekanisme Pengamanan Menggunakan Ssl Encryption," Peranc. Replikasi Basis Data Mysql Dengan Mek. Pengamanan Menggunakan Ssl Encryption, vol. 8, no. 1, pp. 826-836, 2014, doi: 10.12928/jifo.v8i1.a2081.

[5] J.S. Pasaribu, “ Penerapan Framework YII pada Pembangunan Sistem PPDB SMP BPPI
Baleendah Kabupaten Bandung," J. IIm. Teknol. Terap., vol. 3, no. 2, pp. 154- 163, 2017.

[6] Riswan and Y. F. Kesuma, " Analisis Laporan Keuangan Sebagai Dasar Dalam Penilaian Kinerja Keuangan," J. Akunt. Keuang., vol. 5, no. 1, pp. 93- 121, 2014.

[7] M. Sari and N. Dwiyani, " PERANCANGAN APLIKASI E-SETOR ( ELECTRONIC SERVICE MOTOR ) MENGGUNAKAN YII2 FRAMEWORK BERBASIS RESTFUL WEBSERVICE Manda Sari 1) , Nurindah Dwiyani 2) 1," J. Vokasional Tek. Elektron. dan Inform., vol. 7, no. 2, pp. 56- 60, 2019.

[8] W. Mualim and G. U. Putra, " Implementasi Framework Mvc Pada Sistem Informasi Akademik Di Stmik Yadika Bangil," J. SPIRIT, vol. 9, no. 2, pp. 35-39, 2017, doi: 10.1371/journal.pone.0120376.

[9] O. E. Mambu, Y. D. Y. Rindengan, and S. D. S. Karouw, " Pengembangan Aplikasi E-report Layanan Masyarakat untuk Manado Smart City," J. Tek. Inform., vol. 8, no. 1, 2016, doi: 10.35793/jti.8.1.2016.12233.

[10] M. Pongoh, " Analisis Laporan Keuangan Untuk Menilai Kinerja Keuangan Pt. Bumi Resources Tbk.," J. Ris. Ekon. Manajemen, Bisnis dan Akunt., vol. 1, no. 3, pp. 669-679, 2013.

[11] B. Raharjo, Belajar Otodidak Yii Pemrograman Web dengan PHP dan Framework Yii. Bandung: Informatika, 2015.

[12] Y. Mulya, Framework PHP yii 2 :Develop Aplikasi Web dengan cepat dan mudah. Jasakom, 2016.

[13] P. Maharani, Zulhendra, and D. Irfan, “ Aplikasi Majalah Dinding ' Wall On' Berbasis Android Jurusan Teknik Elektronika Fakultas Teknik UNP," vol. 7, no. 1, pp. 6873, 2019.

[14] Kasmir, " Kewirausahaan Edisi Revisi," in Kewirausahaan edisi revisi, Jakarta: PT Rajagrafindo Persada., 2014, p. 314.

[15] S. Arfida and S. Halim, " Perancangan Aplikasi Database Penjualan Pada Kecamatan Jati Agung Lampung Selatan," vol. 01, no. 1, pp. 37- 47, 2015.

[16] H. H. Solihin and A. A. F. Nusa, " Rancang Bangun Sistem Informasi Penjualan, Pembelian dan Persedian Suku Cadang Pada Bengkel Tiga Putra Motor Garut," J. Infotronik, vol. Volume 2, no. 2, pp. 107-115, 2017.

[17] D. F. Syahputra, S. A. Wicaksono, and W. Purnomo, "Pengembangan Sistem Informasi Transaksi Penjualan Dan Komisi Agen Berbasis 
Web ( Studi Pada PT Akademi Pembicara Indonesia )," vol. 3, no. 4, pp. 3451-3460, 2019.

[18] M. R. Syafruddin, I. Aknuranda, and D. Pramono, "Analisis dan Perancangan Sistem Informasi Showroom Mobil (SISMOB) Dengan Pendekatan Berorientasi Objek (Studi Kasus: UD . Tomaru Oto )," vol. 2, no. 10, pp. 36813688, 2018.

[19] E. Prasetio and Y. Hendriyani, "PENGEMBANGAN SISTEM INFORMASI DAN APLIKASI PELAYANAN DI UPT BALAI BAHASA UNP BERBASIS ANDROID," J. Vokasional Tek. Elektron. dan Inform., vol. 7, no. 1, pp. 167174, 2019.

[20] M. Pertiwi, D. Kurniadi, and Y. Hendriyani, "SISTEM INFORMASI PENGELOLAAN PRODUK DAN JASA BERBASIS WEB PADA UNIVERSITAS NEGERI PADNAG," J. Vokasional Tek. Elektron. dan Inform., vol. 91, no. 5, pp. 16891699, 2012, doi: 10.1017/CBO9781107415324.004. 